\title{
Pengelompokan Siswa Penyandang Disabilitas Berdasarkan Tingkat Tunagrahita Menggunakan Algoritma K-Medoids
}

\author{
Dany Pratmanto ${ }^{1}$, Fanny Fatma Wati $^{2}$, Rousyati ${ }^{3}$, Aditia Crisna ${ }^{4}$ \\ 1 STMIK Nusa Mandiri Jakarta,2,3,4Universitas Bina Sarana Informatika \\ 1'dany.dto@nusamandiri.ac.id ,2fanny.ffw@bsi.ac.id, 3 rousyati.rou@bsi.ac.id, \\ 4aditiacr2303@bsi.ac.id
}

\begin{abstract}
Mentally retarded children have obstacles in the activity of the name of the child who still needs proper education in the learning process. SLB Shanti Yoga is one of the best schools that provides educational facilities for children with special needs for people with mental disabilities. The number of criteria determining the level of mentally retarded students makes SLB Shanti Yoga have difficulty in dividing the class according to the results of observations made. So from that research was made to classify data on students with mental retardation to determine the class occupied so that the school can prepare it. The K-Medoids algorithm of clustering techniques can help in grouping students who will occupy classes including light, medium, and heavy classes. The class that has the highest number of students is the heavy mental retardation class while the class that has the lowest number of students is the moderate mental retardation class, with known data grouping results, SLB Shanti Yoga can prepare the class to be used for teaching and learning activities.
\end{abstract}

Keywords: Mentally retarded, data mining, clustering, K-Medoids

Abstrak: Anak tunagrahita mempunyai hambatan dalam beraktivitas nama anak tersebut tetap membutuhkan pendidikan yang layak dalam proses belajar. SLB Shanti Yoga merupakan salah satu sekolah luar bisa yang menyediakan sarana pendidikan bagi anak berkebutuhan khusus penyandang tunagrahita. Banyaknya kriteria penentuan tingkat siswa tunagrahita membuat SLB Shanti Yoga mengalami kesulitan dalam membagi kelas sesuai dengan hasil observasi yang dilakukan. Maka dari itu dibuat penelitian untuk mengelompokkan data siswa penyandang tunagrahita untuk menentukan kelas yang ditempati sehingga pihak sekolah dapat mempersiapkannya. Algoritma K-Medoids dari teknik klastering dapat membantu dalam pengelompokkan siswa yang akan menempati kelas apakah termasuk kelas ringan, sedang, maupun berat. Kelas yang mempunyai jumlah siswa tertinggi yaitu kelas tunagrahita berat sedangkan kelas yang mempunyai jumlah siswa terendah yaitu kelas tunagrahita sedang, dengan diketahui hasil pengelompokka data maka SLB Shanti Yoga dapat mempersiapkan kelas yang akan digunakan untuk kegiatan belajar mengajar.

Kata Kunci : tunagrahita, data mining, clustering, K-Medoids

\section{A. PENDAHULUAN}

Pada tahun 2018 di Indonesia tercatat bahwa anak penyandang disabilitas tunagrahita berjumlah sekitar $2,75 \%$ dari 280 juta atau sekitar 7,7 juta penduduk (mediaindonesia.com). Anak tunagrahita (retardasi mental) merupakan anak yang mempunyai hambatan dalam perkembangan mental maupun intelektual yang mengganggu proses pertumbuhan dibanding anak pada umumnya, sehingga memerlukan perhatian khusus dari keluarga, sekolah maupun lingkungan sosial. Meskipun anak tunagrahita mempunyai hambatan dalam beraktivitas nama anak tersebut tetap membutuhkan pendidikan yang layak dalam proses belajar. SLB Shanti Yoga merupakan salah satu sekolah luar bisa yang menyediakan sarana pendidikan bagi anak berkebutuhan khusus penyandang tunagrahita. Sekolah yang berada di Klaten ini sudah banyak dikenal oleh masyarakat sehingga banyak orang tua menyekolahkan anaknya yang 
menyandang tunagrahita pada SLB tersebut. SLB Shanti Yoga memberikan pelayanan pendidikan pada siswa spesialis penyandang tunagrahita ringan, sedang maupun berat. Pada sekolah tersebut memberikan pendidikan yang berbeda pada setiap klasifikasi siswa tunagrahita. SLB Shanti Yoga dalam penempatan kelas siswa dibagi berdasarkan klasifikasi ringan, sedang dan berat, maka dari itu para guru harus melakukan observasi selama tiga bulan untuk menganalisa klasifikasi siswa berkebutuhan khusus tunagrahita. Banyaknya kriteria penentuan tingkat siswa tunagrahita membuat SLB Shanti Yoga mengalami kesulitan dalam membagi kelas sesuai dengan hasil observasi yang dilakukan. Algoritma K-Medoids dari teknik klastering dapat membantu dalam pengelompokkan siswa yang akan menempati kelas apakah termasuk kelas ringan, sedang, maupun berat. Tujuan dari penelitian ini untuk mengelompokkan data siswa penyandang tunagrahita untuk menentukan kelas yang ditempati sehingga pihak sekolah dapat mempersiapkannya.

\section{B. TINJAUAN PUSTAKA}

1. Penyandang Disabilitas Tunagrahita

Anak penyandang tuna grahita merupakan seseorang yang memiliki kekurangan yang disebabkan karena faktor keturunan, permasalahan saat kelahiran serta faktor lingkungan sosial (Binasiwi,2015:1). Menurut AAMD (American Association of Mental Deficiency) dalam Binasiwi (2015:1) menjelaskan bahwa "Ketunagrahitaan mengacu pada fungsi intelektual umum yang secara signifikan dibawah rata-rata normal bersamaan dengan kekurangan dalam tingkah laku penyesuaian diri dan semua ini berlangsung pada masa perkembangan". Tunagrahita adalah individu yang mempunyai istilah cacat mental, bodoh, dungu, lemah dalam berpikir yang memiliki tingkat inteligensia dibawah rata-rata orang pada umumnya disertai dengan ketidakmampuan dalam beradaptasi perilaku yang muncul pada masa perkembangan (Pandji dan Wardhani,2013:8).

Berdasarkan tinjauan, tunagrahita dapat dikelompokan menjadi beberapa bagian Pieter

(2017:257) antara lain:

a) Berdasarkan Kapasitas Intelektual (skor IQ):

b) Tunagrahita ringan, memiliki IQ 50-70

c) Tunagrahita sedang, memiliki IQ 35-49

d) Tunagrahita berat, memiliki IQ 20-34

e) Berdasarkan kemampuan akademik

f) Tunagrahita ringan mampu mengikuti pelajaran akademik baik disekolah biasa maupun khusus.

g) Tunagrahita sedang hampir tidak mampu mengikuti pelajaran akademik.

h) Tunagrahita berat tidak mampu mengikuti pelajaran akademik oleh sebab itu sepanjang hidupnya akan bergantung pada orang lain.

Berdasarkan penampilan fisik menurut Tan (2017:98), antara lain:

a) Tunagrahita ringan mempunyai ciri fisik seperti orang pada umumnya, mampu mengurus diri sendiri, sedikit mempedulikan lingkungan sekitar, dan gerakan hampir seperti orang pada umumnya.

b) Tunagrahita sedang mempunyai ciri fisik hampir seperti orang pada umunya, mampu mengurus diri sendiri namun tetap dalam pengawasan, kurang memperhatikan lingkungan sekitar dan gerakan hampir seperti orang pada umumnya.

c) Tunagrahita berat mempunyai ciri fisik tidak seimbang misalnya kepala terlalu kecil/besar, tidak mampu mengurus diri sendiri, tidak memperhatikan lingkungan sekitar dan kurang dalam mengkordinasi gerakan yaitu gerakan tidak terkendali.

2. Data Mining

Data Mining merupakan teknologi baru yang sangat berguna untuk membantu perusahaan-perusahaan menemukan informasi yang sangat penting dari gudang data mereka. Beberapa aplikasi datamining fokus pada prediksi, mereka meramalkan apa yang akan terjadi dalam situasi baru dari data yang menggambarkan apa yang terjadi di masa lalu(Witten, Frank dan Hall, 2011).

Data mining merupakan proses ektraksi pengetahuan dari data yang besar. Sesuai fungsinya, data mining adalah proses pengambilan pengetahuan dari volume data yang besar yang disimpan dalam basis data, data warehouse, atau informasi yang disimpan dalam repository (Han \& Kamber, 2006). 
Menurut Daryl Pregibons dalam (Gorunescu, 2011) "Data mining adalah perpaduan dari ilmu statistik, kecerdasan buatan, dan penelitian bidang database". Keduanya memerlukan penyaringan melalui sejumlah besar material, atau menyelidiki dengan cerdas untuk mencari keberadaan sesuatu yang disebut bernilai tadi.

Proses dalam tahapan Data Mining terdiri dari tiga langkah utama, yaitu (Sogala, 2006):

a) Data Preparation

Pada langkah ini, data dipilih, dibersihkan, dan dilakukan preprocessed mengikuti pedoman dan knowledge dari ahli domain yang menangkap dan mengintegrasikan data internal dan eksternal ke dalam tinjauan organisasi secara menyeluruh.

b) Algoritma Data Mining

Penggunaan algoritma data mining dilakukan pada langkah ini untuk menggali data yang terintegrasi untuk memudahkan identifikasi informasi bernilai.

c) Fase Analisa Data

Keluaran dari Data Mining dievaluasi untuk melihat apakah knowledgedomain ditemukan dalam bentuk rule yang telah diekstrak dari jaringan.

3. Algoritma K-Medoids

Algoritma K-Medoids merupakan algoritma yang menggunakan teknik berbasis objek representatif (perwakilan) yang disebut medoids yang mengatasi kelemahan K-Means yang sensitif terhadap derau atau pencilan dengan menghilangkan penggunaan rata-rata untuk memperbarui centroid dan menggantinya dengan objek aktual sebagai representasi dari suatu klaster (Suyanto, 2017). Algoritma K-Medoids merupakan bagian dari partitioning clustering yang cukup efisien untuk dataset yang kecil dengan mencari titil yang paling representatif (medoids) daam sebuah dataset dengan menghitung jarak dalam kelompok dari semua kemungkinan kombinasi dari medoids sehingga jarak antar titik dari suatu cluster kecil dengan jarak titik cluster besar (Zayuk etc, 2017).

\section{METODE PENELITIAN}

Metode penelitian ini menggunakan metode eksperimen sebagai berikut:

1. Pengumpulan Data

Data diperoleh dari seluruh siswa SLB Shanti Yoga yang berjumlah 137 siswa. Data yang diambil berisikan data nilai siswa dari hasil kelas observasi.

2. Penerapan Algoritma

Algoritma yang digunakan untuk perhitungan yaitu algoritma K-Medoids dengan 3 klaster (kelas) dengan menyesuaikan kelas pada SLB Shanti Yoga yaitu kelas ringan, sedang dan berat. Perhitungan dilakukan secara manual dan menggunakan aplikasi rapid miner.

3. Evaluasi Hasil

Hasil yang diperoleh kemudian dievaluasi dan ditampilkan.

Dokumentasi eksperimen.

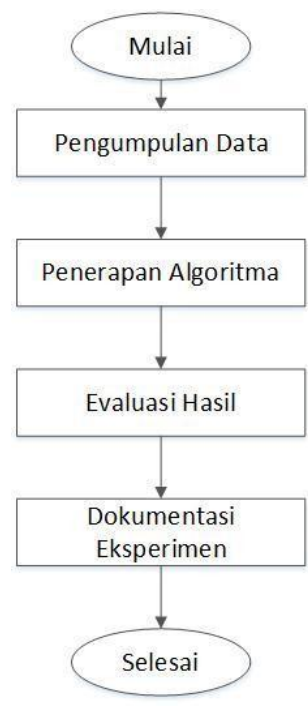

Gambar 1. Skema Penelitian 


\section{HASIL DAN PEMBAHASAN}

\section{Pengumpulan Data}

Teknik pengumpulan data dilakukan dengan mengamati dataset nilai pada kelas obesrvasi siswa SLB Shanti Yoga. Terdapat 5 atribut yang merupakan nis, nama dan nilai siswa. Selain itu data terdiri dari 136 siswa. Adapun contoh dari dataset dapat dilihat pada tabel

Tabel 1. Contoh Dataset

\begin{tabular}{|c|c|c|c|c|c|}
\hline No & NISN & $\begin{array}{l}\text { Nama } \\
\text { Siswa }\end{array}$ & $\mathbf{I Q}$ & NA & NK \\
\hline 1 & 0017742792 & ASR & 33 & 77 & 78 \\
\hline 2 & 0017742790 & AAS & 33 & 76 & 70 \\
\hline 3 & 0017742791 & AAS & 33 & 74 & 66 \\
\hline 4 & 0085238950 & ALW & 33 & 78 & 60 \\
\hline 5 & 0085238952 & ADC & 33 & 70 & 70 \\
\hline 6 & 0078841467 & ADN & 33 & 70 & 70 \\
\hline 7 & 0084451903 & AOW & 33 & 76 & 66 \\
\hline 8 & 0038483536 & $\mathrm{ASH}$ & 33 & 78 & 70 \\
\hline 9 & 0084451904 & AID & 33 & 78 & 79 \\
\hline$\cdots$ & ……………....... & ................. & ........ & $\cdots$ & $\cdots$ \\
\hline $\begin{array}{l}\cdots \\
136\end{array}$ & 0027687460 & ZFTA & $\begin{array}{c}\ldots \ldots . . \\
32\end{array}$ & $\begin{array}{l}\cdots \\
70\end{array}$ & $\begin{array}{l}\cdots \\
71\end{array}$ \\
\hline
\end{tabular}

\section{Penerapan Algoritma}

Penelitian ini menggunakan metode K-Medoids, K-Medoids merupakan bagian dari partitioning clustering. Metode K-Medoids cukup efosien untuk dataset yang kecil. Langkah awal K-Medoids adalah mencari titik yang paling representatif (medoids) dalam sebuah dataset dengan menghitung jarak dalam kelompok dalam semua kemungkinan kombinasi dari medoids sehingga jarak antar titik dalam suatu cluster kecil sedangkan jarak titik antar cluster besar. Langkah-langkah K-Medoids adalah:

1. Pilih poin $\mathrm{k}$ sebagai inisial centroid / nilai tengah (medoids) sebanyak k cluster.

2. Cari semua poin yang paling dekat dengan medoids, dengan cara menghitung jarak vektor antar dokumen dengan menggunakan Euclidian Distance.

Rumusnya adalah sebagi berikut:

$d(x, y)=\sqrt{\sum_{i=1}^{n}|x i-y i|^{2}}$

Dimana:

$d(x, y)=$ jarak antara data ke-i dan data ke-j

xi1 = nilai atribut ke satu dari data ke-i

yj1 = nilai atribut ke satu dari data ke-j

$\mathrm{n}=$ jumlah atribut yang digunakan

3. Secara acak pilih poin yang bukan medoids.

4. Hitung total jarak antar medoids.

5. Jika TD baru <TD awal, tukar posisi medoids dengan medoids baru, jadilah medoids yang baru.

6. Ulangi langkah 2-5 sampai medoids tidak berubah.

\section{Penerapan algoritma dengan perhitungan manual}

Penerapan algoritma dengan perhitungan manual menggunakan 3 cluster dengan 3 iterasi. Iterasi ke-1 menggunakan nilai centroid yaitu:

Tabel 2. Centorid Iterasi Ke-1

\begin{tabular}{|l|l|l|l|l|}
\hline 0073907890 & DA & 44 & 70 & 77 \\
\hline
\end{tabular}


IJSE - Indonesian Journal on Software Engineering, Vol.5, No. 1, Juni 2019, 134-142

\begin{tabular}{|l|c|c|c|c|}
0019734694 & D RNH & 49 & 73 & 74 \\
\hline 0079530780 & DTGS & 49 & 69 & 70 \\
\hline
\end{tabular}

Hasil total jarak dari iterasi 1 yaitu bernilai 1410,86.

Dalam iterasi ke-2 menggunakan nilai centroid yaitu:

Tabel 3. Centorid Iterasi Ke-2

\begin{tabular}{|c|c|c|c|c|}
\hline 0047330230 & HGS & 43 & 75 & 80 \\
\hline 0029083215 & ISP & 45 & 70 & 78 \\
\hline 0082373261 & IAMP & 70 & 76 & 74 \\
\hline
\end{tabular}

Hasil total jarak iterasi ke-2 yaitu 1328,286.

Berdasarkan perbandingan nilai yang didapat dari iterasi ke-1bernilai 1410,86 dan iterasi ke-2 bernilai 1328,286 , nilai dari iterasi ke-2 lebih kecil daripada nilai iterasi ke-1 maka centroid dari iterasi ke-2 dijadikan centroid baru dan melakukan iterasi berikutnya. Iterasi ke-3 menggunakan nilai centroid yaitu:

Tabel 4. Centorid Iterasi Ke-3

\begin{tabular}{|c|c|c|c|c|}
\hline 0085785134 & YR & 55 & 70 & 82 \\
\hline 0037402970 & ZASW & 86 & 67 & 73 \\
\hline 0027687460 & Zh & 32 & 70 & 71 \\
\hline
\end{tabular}

Hasil total jarak iterasi ke-3 yaitu 1629,065.

Berdasarkan perbandingan nilai yang didapat dari iterasi ke-2 bernilai 1328,286 dan nilai dari iterasi ke-3 bernilai 1629,065, nilai dari iterasi ke-3 lebih besar daripada iterasi ke-3 maka perhitungan selesai dengan menggunakan hasil iterasi ke-3.

Tabel 5. Hasil Total Jarak Iterasi Terakhir

\begin{tabular}{|c|c|c|c|c|c|c|c|c|}
\hline \multirow{9}{*}{0} & 9,95 & 18,81 & 11,05 & 8,06 & 8,06 & 6,16 & 3,74 & \multirow{9}{*}{595,06} \\
\hline & 5,00 & 11,05 & 12,08 & 14,04 & 9,95 & 10,44 & 12,04 & \\
\hline & 18,03 & 13,42 & 9,43 & 6,78 & 9,43 & 8,66 & 13,19 & \\
\hline & 6,08 & 9,49 & 8,37 & 12,08 & 11,45 & 11,40 & 13,45 & \\
\hline & 12,08 & 15,84 & 5,92 & 5,66 & 12,25 & 11,53 & 13,49 & \\
\hline & 8,72 & 8,60 & 5,10 & 12,73 & 10,05 & 10,86 & 8,06 & \\
\hline & 18,71 & 14,04 & 13,60 & 13,49 & 5,74 & 4,58 & 18,03 & \\
\hline & 10,05 & 17,23 & 14,87 & 11,00 & 5,00 & 10,05 & 6,08 & \\
\hline & 0,00 & & & & & & & \\
\hline 1 & 18,00 & 16,55 & 12,88 & 23,73 & 19,95 & 16,55 & 0,00 & 108,66 \\
\hline \multirow{9}{*}{2} & 15,62 & 16,76 & 13,42 & 9,43 & 8,54 & 12,65 & 13,00 & \multirow{9}{*}{925,33} \\
\hline & 12,69 & 13,45 & 13,75 & 11,75 & 18,41 & 8,66 & 8,54 & \\
\hline & 10,20 & 9,49 & 10,68 & 17,44 & 9,90 & 15,62 & 14,73 & \\
\hline & 12,37 & 7,07 & 10,44 & 10,63 & 11,40 & 12,04 & 10,05 & \\
\hline & 12,81 & 5,39 & 12,08 & 10,44 & 13,45 & 19,10 & 17,80 & \\
\hline & 15,26 & 12,21 & 8,72 & 14,70 & 12,81 & 9,90 & 13,42 & \\
\hline & 13,75 & 13,15 & 10,77 & 18,03 & 11,75 & 13,42 & 16,79 & \\
\hline & 8,72 & 11,18 & 21,00 & 14,97 & 12,53 & 13,64 & 7,21 & \\
\hline & 10,20 & 21,28 & 14,42 & 8,72 & 14,56 & 12,69 & 9,43 & \\
\hline
\end{tabular}




\begin{tabular}{|c|c|c|c|c|c|c|}
12,21 & 18,03 & 14,46 & 13,00 & 8,06 & 22,36 & 23,43 \\
\hline 16,76 & 0,00 & & & & & \\
\hline
\end{tabular}

\section{Evaluasi Hasil}

Dari hasil eksperimen clustering data siswa, diperoleh grafik sebagai berikut yang tertera pada gambar:

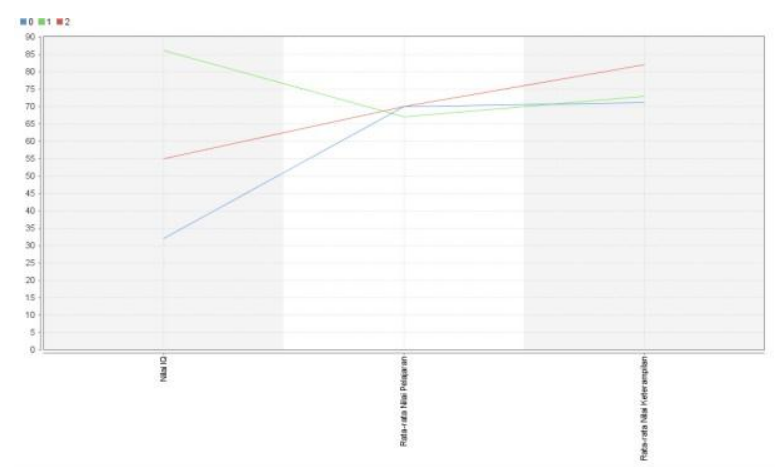

Gambar 2. Grafik Time Process Berita

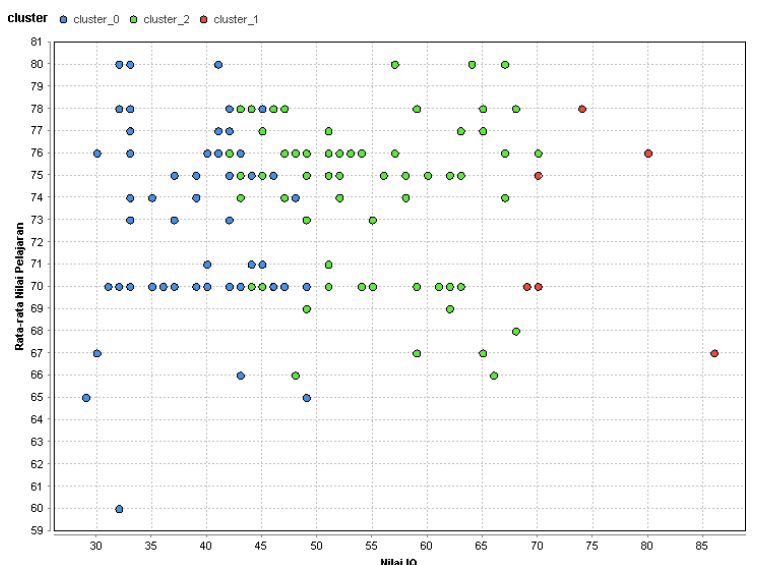

Gambar 3. Grafik Hasil Clustering

Informasi yang bisa diperoleh dari hasil eksperimen custering pada data siswa yang berjumlah 136 record data, dapat dikelompokkan menjadi 3 kelompok (cluster) yaitu tunagrahita ringan, sedang dan berat.

Cluster pertama yaitu sebagai kelompok kelas tunagrahita ringan dengan jumlah 57 siswa dapat dilihat pada tabel berikut:

Tabel 6. Data Siswa Tunagrahita Ringan

\begin{tabular}{|l|l|l|}
\hline \multicolumn{3}{|l|}{ Nama Siswa } \\
\hline ARS & HD & RVK \\
\hline ALW & IDC & RPP \\
\hline ADN & KDS & RK \\
\hline AON & LB & RR \\
\hline ASM & MDF & RA \\
\hline AFD & MED & RDK \\
\hline ANDP & MSU & RDR \\
\hline
\end{tabular}




\begin{tabular}{|l|l|l|}
\hline AR & AFDR & RK \\
\hline ADN & MIM & RR \\
\hline BN & MN & SNA \\
\hline BW & MRA & SYS \\
\hline EH & MRS & VF \\
\hline ENW & MSK & VWN \\
\hline ERC & MTN & WA \\
\hline EAO & MHW & YAN \\
\hline FIP & NSK & YL \\
\hline FT M & Ne & ZF \\
\hline FI & NDH & \\
\hline GAA & NS & \\
\hline HHM & OT & \\
\hline
\end{tabular}

Cluster kedua yaitu sebagai kelompok kelas tunagrahita ringan dengan jumlah 7 siswa dapat dilihat pada tabel berikut:

Tabel 7. Data Siswa Tunagrahita Sedang

\begin{tabular}{|l|}
\hline Nama Siswa \\
\hline CAS \\
\hline LR \\
\hline LH \\
\hline RDS \\
\hline RQ \\
\hline SEW \\
\hline ZAW \\
\hline
\end{tabular}

Cluster ketiga yaitu sebagai kelompok kelas tunagrahita ringan dengan jumlah 72 siswa dapat dilihat pada tabel berikut:

Tabel 8. Data Siswa Tunagrahita Berat

\begin{tabular}{|l|l|}
\hline \multicolumn{2}{|l|}{ Nama Siswa } \\
\hline AAS & BRC \\
\hline AS & BCP \\
\hline ADC & BPKP \\
\hline AID & BMRD \\
\hline AR & BA \\
\hline AWG & CD \\
\hline AI & CAK \\
\hline AN & DS \\
\hline AD & DSTR \\
\hline AGS & DP \\
\hline AMK & DR \\
\hline AM & DA \\
\hline AR & DRNH \\
\hline
\end{tabular}




\begin{tabular}{|l|l|}
\hline AHC & DTGS \\
\hline AJR & DP \\
\hline ANC & DRPD \\
\hline AS & DA \\
\hline AI & DAA \\
\hline AFN & ER \\
\hline$\ldots \ldots \ldots .$. & $\ldots \ldots \ldots$ \\
\hline$\ldots \ldots \ldots \ldots$ & $\ldots \ldots \ldots$ \\
\hline YNR & YR \\
\hline
\end{tabular}

Implementasi data menggunakan aplikasi rapid miner:

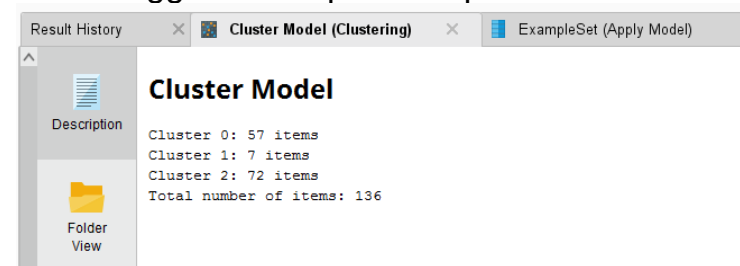

Gambar 4. Hasil Total Pengelompokkan Data

\section{Dokumen Eksperimen}

Dataset diambil dari data siswadalam bentuk excel di import ke aplikasi rapid miner . Adapun hasil import data dari dataset ditunjukkan sebagai berikut:

\begin{tabular}{|c|c|c|c|c|c|c|c|}
\hline \multirow{2}{*}{\multicolumn{2}{|c|}{$\frac{\checkmark}{N I S N}$}} & \multicolumn{2}{|l|}{$\checkmark$} & \multicolumn{2}{|l|}{$\checkmark$} & \multicolumn{2}{|l|}{$\checkmark$} \\
\hline & & \multicolumn{2}{|l|}{ Nilai IQ } & \multicolumn{2}{|c|}{ Nilai Akader } & \multicolumn{2}{|c|}{ Nilai Keterar } \\
\hline real & $\nabla$ & integer & $\nabla$ & integer & $\nabla$ & integer & $\boldsymbol{\nabla}$ \\
\hline id & $\nabla$ & attribute & $\nabla$ & attribute & $\nabla$ & attribute & $\boldsymbol{\nabla}$ \\
\hline \multicolumn{2}{|c|}{84451903} & \multicolumn{2}{|l|}{30} & \multicolumn{2}{|l|}{76} & \multicolumn{2}{|l|}{66} \\
\hline \multicolumn{2}{|c|}{38483536} & \multicolumn{2}{|l|}{32} & \multicolumn{2}{|l|}{78} & \multicolumn{2}{|l|}{70} \\
\hline \multicolumn{2}{|c|}{84451904} & \multicolumn{2}{|l|}{59} & \multicolumn{2}{|l|}{78} & \multicolumn{2}{|l|}{79} \\
\hline \multicolumn{2}{|c|}{98772475} & \multicolumn{2}{|l|}{55} & \multicolumn{2}{|l|}{73} & \multicolumn{2}{|l|}{74} \\
\hline \multicolumn{2}{|c|}{53905268} & \multicolumn{2}{|l|}{51} & \multicolumn{2}{|l|}{70} & \multicolumn{2}{|l|}{70} \\
\hline
\end{tabular}

Gambar 5. Import Data Dasi Excel

Data yang sudah diimport kemudian dilakukan proses clustering dengan membagi data menjadi 3 custer (k). Hasil dari proses tersebut kemudian dieksport dalam bentuk file excel. Berikut merupakan proses clustering:

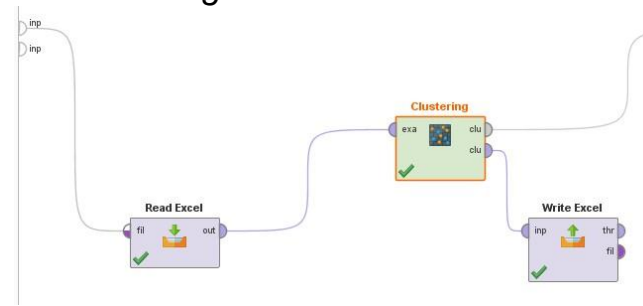

Gambar 6. Proses Clustering Data

Adapun hasil proses clustering yang telah diolah sebagai berikut: 


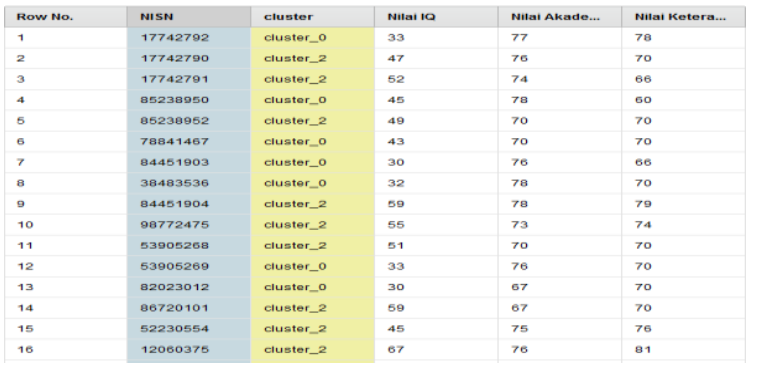

Gambar 7. Hasil Clustering Data

\section{E. KESIMPULAN}

Dari hasil penelitian yang telah diakukan maka dapat disimpulkan bahwa pengelompokkan data siswa SLB Shanti Yoga yang terdiri dari 136 record menghasilkan 3 cluster dengan cluster pertama yaitu kelas tunagrahita ringan terdiri dari 57 record data siswa, cluster kedua yang merupakan kelas tunagrahita sedang terdiri dari 7 record data siswa dan kelas tunagrahita berat yang termasuk ke dalam cluster ketiga terdiri dari 72 data record. Kelas yang mempunyai jumlah siswa tertinggi yaitu kelas tunagrahita berat sedangkan kelas yang mempunyai jumlah siswa terendah yaitu kelas tunagrahita sedang, dengan diketahui hasil pengelompokka data maka SLB Shanti Yoga dapat mempersiapkan kelas yang akan digunakan untuk kegiatan belajar mengajar.Diharapkan pada penelitian selanjutnya sebaiknya memperlihatkan nilai-nilai cluster hasil dari K-Medoids sehingga didapatkan nilai hasil akurasi, recall, dan precision setelah proses clustering.

\section{REFERENSI}

Gorunescu, Florin. (2011). Data Mining Concept, Model and Technique. Verlag Berlin Heidelberg: Springer.

Han, J.,\& Kamber, M. (2006). Data Mining Concept and Tehniques. San Fransisco: Morgan Kauffman. ISBN 13: 978-1-55860-901-3

Mediaindonesia.com

Pandji, Dewi dan Wardhani, Winda. (2013). Sudahkah Kita Ramah Anak Special Needs?. Jakarta: PT Elex Media Komputindo

Panti Asuhan Binasiwi. (2015). Menghapus Stigma Membangun Percaya Diri Anak Tunagrahita Melalui Pemberdayaan Partisipatoris. Yogyakarta: Lintang Pustaka Utama.

Pieter, Herri Zan. (2017). Dasar-Dasar Komunikasi Bagi Perawat. Yogyakarta: PT. Kharisma Putra Utama

Suyanto. (2017). Data Mining Untuk Klasifikasi dan Klasterisasi Data. Bandung:Informatika. Tan, Thomas. (2017). Teaching Is an Art: Maximize Your Teaching. Yogyakarta: Deepublish Witten, H. I., Eibe, F., \& Hall, A. M. (2011). Data Mining Machine Learning Tools and Techiques. Burlington: Morgan Kaufmann Publisher.

Zayuka, Harival, Nasution, S.M, Purwanto Yudha. (2017). Perancangan Dan Analisis Clustering Data Menggunakan Metode K-Medoids Untuk Berita Berbahasa Inggris Design And Analysis Of Data Clustering Using K-Medoids Method For English News. Bandung: E-Proceeding Of Engineer 